\title{
A INVENÇÃO DO ARQUIVO PESSOAL DE SANTOS DUMONT
}

\section{THE INVENTION OF SANTOS DUMONT'S PERSONAL FILE}

\section{Bárbara Cristina Barbosa Pinto da Silva*}

Resumo: O trabalho objetiva discutir como se deu a constituição do que hoje se conhece como o Arquivo Pessoal de Santos Dumont. O referido conjunto documental foi doado ao Centro de Documentação da Aeronáutica (CENDOC), Organização Militar (OM) do Comando da Aeronáutica (COMAER), em 2004 e é constituído por 2716 unidades documentais, sendo 764 documentos iconográficos e 1,57 metros lineares de documentos textuais, reunidos pelo pai da Aviação até 1932, além dos acréscimos selecionados pelo Brigadeiro Lavenère-Wanderley, na década de 1960. Esse conjunto documental, apesar de não ser fruto das funções e atividades desenvolvidas por Dumont, é representativo de sua trajetória numa perspectiva pessoal, visto que esse conjunto fora acumulado a partir de clippings ora solicitados por Santos Dumont. No nível de conteúdo, os documentos refletem suas atividades. Esse conjunto hoje possui, portanto, força de representação documental sobre a vida de Santos Dumont e apresenta documentos provenientes da ação do Santos Dumont de agregar registros sobre sua vida. A pesquisa se fundamentou em problematizar o processo de constituição do conjunto documental que hoje é considerado o arquivo pessoal de Santos Dumont. Nesse sentido buscou-se, através de diálogos com a teoria arquivística, descrever a história arquivística do acervo, a fim de comparar o processo de produção desse arquivo com o de um arquivo pessoal. Espera-se, com este trabalho, demonstrar que, apesar não podermos considerá-lo, no sentido canônico da definição, um arquivo pessoal, este é sim o arquivo pessoal de Santos Dumont, a partir da história arquivística apresentada.

Palavras-chave: Arquivo Pessoal. Santos Dumont. Constituição.

Abstract: This paper aims to discuss how the constitution of what is known today as the Santos Dumont Personal Archive took place. This set of documents was donated to the Aeronautics Documentation Center (CENDOC), Military Organization (OM) of the Aeronautics Command (COMAER), in 2004 and consists of 2716 documentary units, 764 iconographic documents and 1.57 linear meters of textual documents, gathered by the father of Aviation until 1932, in addition to the additions selected by Brigadier Lavenère-Wanderley in the 1960s. This documentary set, although not the

\footnotetext{
Artigo apresentado e publicado nos anais do Congresso Nacional de Arquivologia, no ano de 2018.

** Arquivista, formada em 2009, pela UNIRIO, com Curso de Extensão em Gestão do Conhecimento pela FGV e com Pós Graduação em Inteligência Competitiva pelo SENAC. Mestre em Gestão de documentos e Arquivos pela UNIRIO. Trabalha na Força Aérea Brasileira desde de 2013, atualmente como Chefe da Seção de Normatização em Arquivologia e da Seção da Capacitação em Arquivologia.
} 
result of the functions and activities developed by Dumont, is representative of his trajectory from a perspective. personal, since this set was accumulated from clippings now requested by Santos Dumont. At the content level, documents reflect your activities. This set has, therefore, the power of documentary representation about the life of Santos Dumont and presents documents coming from Santos Dumont's action of aggregating records about his life. The research was based on problematizing the process of constitution of the documentary set that today is considered the personal archive of Santos Dumont. In this sense, we sought, through dialogues with the archival theory, to describe the archival history of the collection, in order to compare the process of producing this archive with that of a personal archive. It is hoped, with this work, to demonstrate that, although we can not consider it, in the canonical sense of the definition, a personal archive, this is the personal archive of Santos Dumont, based on the archival history presented.

Keywords: Personal Archive. Santos Dumont. Constitution. 


\section{INTRODUÇÃO}

No presente trabalho, sob a expressão invenção, pretende-se discutir como se deu a constituição do que hoje se conhece como o Arquivo Pessoal de Santos Dumont. O referido conjunto documental, objeto empírico deste artigo, foi doado ao Centro de Documentação da Aeronáutica (CENDOC), Organização Militar (OM) do Comando da Aeronáutica (COMAER), em 2004 e é constituído por 2716 unidades documentais, sendo 764 documentos iconográficos e 1,57 metros lineares de documentos textuais, reunidos pelo pai da Aviação até 1932, além dos acréscimos selecionados pelo Brigadeiro Lavenère-Wanderley, na década de 1960.

Essa investigação sobre a constituição do chamado Arquivo Pessoal de Santos Dumont encontra lastro na trajetória da autora deste artigo desde quando a mesma cursou a graduação em arquivologia e teve os primeiros contatos com os arquivos pessoais no Centro de Pesquisa e Documentação de História Contemporânea do Brasil (CPDOC), especificamente, o arquivo pessoal de Getúlio Vargas. A partir dessa experiência foi possível reconhecer uma dinâmica complexa, ainda que pouco arquivística em termos canônicos, entre acervos pessoais e seus titulares.

Desse modo, parte-se de elementos da biografia da pessoa que dá nome ao conjunto documental custodiado pelo CENDOC, considerando a trajetória de Santos Dumont, desde seu nascimento até o seu falecimento; em seguida, aborda-se a história arquivística do acervo, dimensão em que se problematiza a constituição do conjunto documental, desde o momento em que Santos Dumont decide reunir e acumular documentos, até o recolhimento pela família, incluindo as diversas interferências, e finalmente a doação ao CENDOC há 14 anos. A autora deste estudo atuou no processamento técnico arquivístico dessa documentação, como Chefe do Projeto Acervo Santos Dumont, nos anos de 2014 e 2015.

Uma referência conceitual central nesta pesquisa é a caracterização da ideia de arquivo formulada por Heymann (2009), ao reconhecê-lo como constructo social resultante da ação da entidade produtora de arquivo, mas também inclui organizadores e custodiadores em diferentes tempos e circunstâncias, com suas próprias seleções e classificações. 
Alberto Santos Dumont (1873 - 1932) foi um inventor brasileiro, conhecido mundialmente como o pai da aviação. No final do século XIX, sensibilizado pelo surgimento do motor a gasolina, Santos Dumont buscou realizar seu ideal, de criar um aparelho que permitisse o homem voar controlando seu próprio curso. Santos Dumont, ao se mudar para Paris, aprofundou-se em estudos sobre mecânica e motor de combustão. A dirigibilidade parecia ser o que interessava a Santos Dumont.

No conjunto documental denominado Santos Dumont, no CENDOC, estão indiciadas as histórias por trás de cada invento, suas criações e seus objetivos. Os documentos apontam, de uma maneira geral, para a trajetória desse aeronauta brasileiro. Há registros de sua vida pessoal e profissional através de artigos de jornal, cartas e fotografias. Durante o processamento arquivístico, notou-se uma significativa quantidade de artigos de jornais e fotografias que sugerem uma intenção do titular em comprovar seus feitos e inventos por intermédio dessa seleção de documentos.

O arquivo pessoal de Santos Dumont, até 2014, parece não ter recebido tratamento arquivístico. Inicialmente os documentos foram encaminhados para o Museu de Astronomia e Ciências Afins (MAST) com o objetivo de receberem tratamento de conservação. Após esse tratamento, os documentos retornaram para - CENDOC. A partir de então, as intervenções técnicas foram realizadas com aprofundamento conceitual, enquadramento na teoria arquivística e debate em torno dos arquivos pessoais. Surgiram novos questionamentos e expectativas de novas respostas ao trabalho prático, o que trouxe a autora desta pesquisa ao Mestrado Profissional de Gestão de Documentos e Arquivos.

Diante do exposto, torna-se relevante caracterizar o processo de construção do conjunto documental que hoje é reconhecido como o Arquivo Pessoal de Santos Dumont, especificamente, reconhecer como foi a constituição do acervo à luz de diálogos com a teoria/metodologia arquivística no que diz respeito ao campo dos arquivos pessoais e descrever a história arquivística desse acervo, desde sua produção/acumulação até seu processamento técnico, visando a sua disponibilização para pesquisa. 
Os arquivos pessoais são um tema de discussão no universo arquivístico datado de 1990, graças ao aprofundamento teórico sobre o tema, deixando de ser apenas textos puramente técnicos. Os arquivos pessoais eram considerados como secundário frente ás instituições oficiais. (ASSIS, 2009, p. 41).

O conceito apresenta nuances e problemáticas, principalmente no se refere a sua relação com a teoria/metodologia arquivística. Além disso, o caráter orgânico que caracteriza um arquivo não era reconhecido num arquivo pessoal, já que a acumulação documental não seria natural e considerada carregada de subjetivismo. $\mathrm{O}$ arquivo pessoal por estar associado à construção da imagem do indivíduo titular não teria a acumulação necessária e espontânea dos documentos administrativos e por isso era renegado a segundo plano. (ASSIS, 2009, p. 42).

Durante muito tempo o que se entendia por arquivos pessoais, era compreendido pela reunião de manuscritos de origem privada e considerado como documentos históricos, sendo relegados a bibliotecas e museus (HEYMANN, 2009, p. 43). Os manuscritos citados também podiam ser familiares, em muitos casos.

Ao iniciarmos os estudos na seara da arquivologia é apresentada a distinção dos arquivos segundo a natureza - pública ou privada - de acordo com a entidade que os acumulou, criando, assim, duas categorias para, então, designá-los e caracterizá-los, podendo ser os "arquivos públicos", constituídos no curso das atividades dos órgãos ligados à administração pública, ou ainda os "arquivos privados", considerando tanto os conjuntos de documentos produzidos por instituições privadas quanto àqueles acumulados por pessoas ou famílias. Cabe salientar que esta inserção de arquivos acumulados por pessoas na definição de arquivos privados tem como base a natureza jurídica dos conjuntos documentais produzidos e acumulados. (HEYMANN, 2009, p. 43).

Nos dias atuais, a compreensão do que seria um arquivo pessoal foi ampliada, graças a uma valorização destes, tanto como arquivo, quanto como fonte de pesquisa. Ressalta-se que muitas instituições, principalmente as que têm uma dimensão mais cultural, têm se sensibilizado no sentido de recebê-los e tratá-los, considerando principalmente seu evidente interesse para a pesquisa, além do seu papel na constituição da memória social. 
crescente interesse pelos arquivos pessoais se deve a uma mudança de paradigma nas práticas historiográficas. Assim, Cristopher Prochasson aponta dois fatores que podem deixar claro esse interesse pelos arquivos pessoais: o primeiro é o impulso experimentado pela história cultural e multiplicação dos trabalhos sobre os intelectuais; e o segundo motivo está vinculado à mudança da escala de observação do social, que levou, por meio da micro-história e da antropologia histórica, à busca por fontes menos seriais e mais qualitativas. (PROCHASSON, 1998).

O avanço da prática na história trouxe à tona a necessidade de uma maior quantidade de fontes para as suas pesquisas e a sistematização destas. Principalmente o desenvolvimento da micro-história e da história cultural, de acordo com Santos (2012) fizeram com que os arquivos pessoais adquirissem importância enquanto fontes de estudo historiográficos. Thomson (1997, p. 70) relata o aumento do interesse pelos historiadores sobre biografias quando argumenta sobre a relação entre memória e subjetividade: "Alguns historiadores orais têm participado desses debates, embora nos últimos anos tenha havido um extraordinário crescimento do interesse pela pesquisa sobre histórias de vida".

Heymann (1997, p. 43) aponta que a primeira menção a arquivos constituídos por indivíduos aparece em 1928, no manual do arquivista italiano Eugenio Casanova (1928, p. 9), que define os arquivos como [...] "acumulação ordenada de documentos criados por uma instituição ou pessoa no curso de sua atividade e preservados para a consecução de seus objetivos políticos, legais e culturais, pela referida instituição ou pessoa".

Ao focar a pesquisa sobre arquivos privados, Santos (2012, p. 28) afirma que a publicação tida como marco para uma primeira aproximação dos profissionais brasileiros com a questão dos arquivos pessoais é a obra de Theodore R. Schellenberg, de 1963, Public and Private records: their arrangement and description. Nesta obra, Schellenberg apresenta em seu livro como os "papéis privados" ou "manuscritos históricos" despertaram interesse das bibliotecas públicas, sobretudo graças às atividades das sociedades históricas e colecionadores, no século XIX e início do século XX. Percebe-se, portanto, que os arquivos de pessoas já eram contemplados, mesmo antes de se iniciarem as discussões sobre o tema na área arquivística. 
A Lei o 8.159, de 8 de janeiro de 1991, conhecida como a Lei de Arquivos Brasileira, define arquivos, em seu artigo $2^{\circ}$, como os conjuntos de documentos produzidos e recebidos por órgãos públicos, instituições de caráter público e entidades privadas, em decorrência do exercício de atividades específicas, bem como por pessoa física, qualquer que seja o suporte da informação ou a natureza dos documentos. A mesma lei considera arquivos privados, em seu artigo 11, como "os conjuntos de documentos produzidos ou recebidos por pessoas físicas ou jurídicas, em decorrência de suas atividades. O artigo 12 da Lei determina que os arquivos privados podem ser identificados pelo Poder Público como de interesse público e social, desde que sejam considerados como conjuntos de fontes relevantes para a história e desenvolvimento científico nacional. (BRASIL, 1991).

Diante do exposto até então, as definições de arquivos até agora apresentadas e analisadas têm um viés que contempla arquivos pessoais. É claro, apenas, que a existência de arquivos pessoais é reconhecida, visto o reconhecimento de que uma pessoa acumula e recebe documentos decorrentes de atividades por ela realizadas e que isso constitui um arquivo.

A conceituação de arquivos pessoais está embutida na própria definição geral de arquivos privados, quando se afirmar tratar-se de papéis produzidos/recebidos por entidades ou pessoas físicas de direito privado. $\mathrm{O}$ que se pode aqui especificar é que, sendo papéis ligados à vida, à obra e às atividades de uma pessoa, não são documentos funcionais e administrativos no sentido que possuem os de gestão de uma casa comercial ou de um sindicato laboral. São papéis ligados à vida familiar, civil, profissional e à produção política e/ou intelectual, científica, artística de estadistas, políticos, artistas, literatos, cientistas etc. (BELLOTTO, 2004, p. 256).

Nesta categoria, arquivos privados, o Dicionário Brasileiro de Terminologia Arquivística (ARQUIVO NACIONAL, 2005) inclui arquivos de entidades coletivas de direito privado, famílias ou pessoas.

Ainda nos anos 2000, foi publicada pelo Conselho Nacional de Arquivos (CONARQ), a Resolução o 17, 25 de julho de 2003, que dispõe sobre os procedimentos relativos à declaração de interesse público e social de arquivos 
privados de pessoas físicas ou jurídicas que contenham documentos relevantes para a história, a cultura e o desenvolvimento nacional ${ }^{1}$.

De acordo com Santos (2012, p. 28), a doação do arquivo do ex-presidente Getúlio Vargas ao Centro de Pesquisa e Documentação de História Contemporânea do Brasil (CPDOC/FGV), foi uma experiência inspiradora para o surgimento de instituições dedicadas à preservação e à difusão de acervos. A meu ver, esta ação também foi importante para a Arquivologia, além de incentivadora a famílias e personalidades para que estas divulgassem relíquias documentais guardadas.

Referenciando Santos (2012, p. 29), novamente, na década de 1980, o CPDOC/FGV tornou-se um centro especializado na guarda de arquivos privados pessoais de representantes da elite política, atuando, então, como referência para as mais diversas instituições. A prática dos profissionais envolvidos trouxe singularidade ao tratamento arquivístico dos arquivos privados pessoais, visto que os profissionais se dedicavam a compreensão do universo dos arquivos pessoais, repletos de surpresas, componentes inusitados e desafios metodológicos. E foi justamente esta singularidade que lançou as bases de um método de organização de arquivos e coleções pessoais, largamente disseminado no Brasil.

Mantendo o enfoque desta pesquisa nos arquivos pessoais, devemos considerar a relevância como fonte histórica destes e sua importância. Esses documentos, reunidos e acumulados por pessoas físicas, podem complementar, por exemplo, informações oficiais, como no caso dos arquivos recolhidos pelo CPDOC/FGV ou ainda pelo Museu de Astronomia e Ciências Afins (MAST). Portanto, os arquivos pessoais vêm contribuir com o entendimento de questões sociais, culturais, práticas científicas, e assim complementar as já tradicionais fontes de informação, as institucionais.

Do ponto de vista da produção acadêmica sobre o tema no Brasil, pode-se destacar a definição de arquivos pessoais defendida por Heloísa Liberali Bellotto, reconhecida profissional de São Paulo, com atuação em todo o país:

Assim, pode-se definir arquivo pessoal como o conjunto de papéis e material audiovisual ou iconográfico resultante da vida e da obra/atividade de estadistas, políticos, administradores, líderes de categorias profissionais,

${ }^{1}$ O que também foi tratado na lei de Arquivos. 
cientistas, escritores, artistas e etc. Enfim, pessoas cuja maneira de agir, pensar, atuar e viver possa ter algum interesse para as pesquisas nas respectivas áreas onde desenvolveram suas atividades; ou ainda, pessoas detentoras de informações inéditas em seus documentos que, se divulgadas na comunidade científica e na sociedade civil, trarão fatos novos para as ciências, a arte e a sociedade. (BELLOTTO, 2006, p. 266).

Diante do exposto, voltemo-nos para a questão central desta pesquisa, o processo de constituição do conjunto documental que hoje é considerado o arquivo pessoal de Santos Dumont, processo que aqui denominamos de "invenção". Ao utilizarmos Bellotto como referência para definirmos arquivos pessoais, parece-nos que o acervo de Santos Dumont poderia ser considerado um arquivo pessoal. A autora afirma que um arquivo pessoal é composto por papéis e materiais resultantes da vida e da obra de seu titular. Se não investigarmos a história arquivística de nenhum acervo, não poderemos defini-lo com arquivo pessoal ou coleção, por exemplo. E esse ponto é fundamental para complementar o que será apresentado a seguir.

Primeiro, tratemos do que hoje é considerado o arquivo pessoal de Santos Dumont, sob custódia do CENDOC: há documentos produzidos por Santos Dumont, além de documentos por ele acumulados. Parece ser essa a primeira iniciativa de constituição e acumulação de papéis sobre a vida do inventor, realizada pelo próprio. Mas há, ainda, em outro tempo e outras circunstâncias, a participação de outros agentes na ampliação do conjunto documental e cujo protagonismo nessa ampliação foi o do Tenente Brigadeiro Lavenère-Wanderley. Lavenère-Wanderley foi casado com a sobrinha-neta de Santos Dumont, Sophia Helena. Daí sua relação direta com o inventor. Além disso, Lavenère era historiador por natureza, publicou o Livro História da Força Aérea, sua primeira edição em 1967, e foi eleito sócio honorário do Instituto Histórico e Geográfico Brasileiro (IHGB) em 26 de julho de 1972, passando a sócio efetivo em 15 de dezembro de 1975.

Uma das questões iniciais que o conjunto documental doado ao CENDOC trazia era relacionado ao que fora produzido e acumulado por Santos Dumont anteriormente à interferência do Tenente Brigadeiro Lavenère-Wanderley. Não há registros de que Santos Dumont havia organizado seus documentos nem como os havia organizado. 
Ao eclodir a Revolução Constitucionalista de 1932, a parte da família que residia em São Paulo, cidade que foi mais duramente atingida, receou uma invasão e extravio dos pertences pessoais que se encontravam na casa de Petrópolis, pois ela ficava desguarnecida de segurança. O Sr. Jorge Toledo Dodsworth, preocupado, trouxe os referidos pertences, e dentre eles, um baú de vime fechado com os "papéis" de Santos-Dumont. Em 1969, ao baú foi reencontrado e deixado sob a guarda do Tenente Brigadeiro Lavenère-Wanderley. $O$ Brigadeiro, nos três anos subsequentes, cuidou dos documentos, organizando-os em cinco volumes encadernados que juntos possuem em torno de 2200 unidades documentais, testemunhos da trajetória de Santos-Dumont durante os anos de 1899 a 1903. Os registros posteriores a essa data foram conseguidos e reunidos pelo Tenente Brigadeiro Lavenère-Wanderley.

Os anos se passaram e a família percebeu a necessidade de o conjunto documental receber um tratamento que Ihe desse maior visibilidade. Alberto Dodsworth Wanderley, filho do Tenente Brigadeiro Lavenère-Wanderley, foi um dos membros da família que, junto com sua mãe, participou ativamente da busca por uma instituição que recebesse o acervo e o disponibilizasse para consulta.

\begin{abstract}
Após o falecimento do meu avô, minha avó começou a desmontar a casa. Pediu então a meu pai que fosse ao porão ver um cesto de vime que continha, segundo ela, uma série de papéis antigos. Era para ele ver o que prestava e jogar fora o que não prestasse. Quando meu pai viu que aquilo não era papel velho, que ali havia artigos de jornal do mundo inteiro com notícias relacionadas a Santos-Dumont, ele disse à minha avó que ia recolher tudo. Como historiador que era, reconheceu aquele material como documentos históricos e se interessou em fazer ele mesmo sua classificação? .
\end{abstract}

Foram consultadas várias entidades e o CENDOC se interessou em receber esse conjunto documental denominado Santos Dumont. A primeira conversa se deu por intermédio do Arquivo Nacional, procurado em 2003. Em 2004, o CENDOC se comprometeu no Termo de Doação assinado com a família a realizar a organização arquivística do acervo, conservá-lo e divulgá-lo por meio de catálogos, apresentações multimídia e instituições de pesquisa, entre outras formas, além de

\footnotetext{
${ }^{2}$ Entrevista concedida em 2015 pelo Sr. Alberto Dodsworth Wanderley ao Jornal Estadão, Especial a Redescoberta de Santos Dumont.
} 
fazer pelo menos três exposições por ano. A exigência era de que o acervo fosse democratizado, que não se limitasse à manutenção e sim fosse posto à disposição não só de pesquisadores, mas de colégios e público em geral.

Observa-se que, apesar de estar registrado no Termo de Doação, em sua primeira cláusula, que os documentos pertencentes ao acervo Santos Dumont foram compilados pelo Tenente Brigadeiro Lavenère-Wanderley, não há qualquer registro de uma provável inquietude, por parte do CENDOC, da interferência realizada por Lavenère no acervo. Percebe-se que isto nunca foi o foco dos holofotes: o nome Santos Dumont obteve maior visibilidade do que a história arquivística do acervo, o que se confirma dada a quantidade de atividades a serem realizadas em prol da divulgação do acervo, o que acabou por deixar a história arquivística de lado.

Por não possuir uma política de aquisição de acervos, nem padrões próprios e definidos para o tratamento de arquivos pessoais, o CENDOC, na pessoa de uma militar arquivista, necessitou criar um quadro de arranjo inspirando-se em boas práticas vistas em outras instituições, como as praticadas pelo MAST ${ }^{3}$.

No conjunto documental de Santos Dumont, alguns problemas foram identificados logo no início do processamento técnico arquivístico. Primeiramente, é importante salientar que os documentos foram doados ao CENDOC como livros. $O$ Tenente Brigadeiro Lavenère-Wanderley, a partir dos documentos reunidos por Santos Dumont, encadernou os documentos e os organizou em cinco volumes, mais um, chamado de avulsos, após ter incluído muitos outros documentos sobre o parente famoso. Esse aspecto da história do arquivo foi descoberto após o início do tratamento técnico. Os volumes foram desmontados para que recebessem tratamento de conservação e restauro, e assim foram entregues ao CENDOC, como unidades documentais, da mesma maneira que o Tenente Brigadeiro LavenèreWanderley os encontrou.

Com a intenção de se manter os documentos de acordo com o que fora encontrado pela família, ou seja, em unidades documentais e não encadernados, era necessário definir um quadro de arranjo que fosse mais eficaz para o adequado

\footnotetext{
${ }^{3}$ Por mais que o MAST tenha sido a instituição responsável pelo tratamento de conservação com vistas à salvaguarda da documentação, a referida instituição não participou do processamento técnico arquivístico. Suas práticas apenas inspiraram o tratamento a ser realizado pelos militares do CENDOC.
} 
processamento técnico. Sobre isso, Lopez (1999, p. 69) pontua que o arranjo arquivístico deve garantir a devida contextualização dos documentos, resgatando as funções e atividades geradoras dos registros e respeitando o princípio da proveniência.

Para resolver tal questão, foi seguido o modelo de arranjo aplicado pelo MAST até o ano de 2013, não só para o arquivo pessoal de Santos Dumont, como também para outro arquivo pessoal já doado. Nesse sentido, foi adotado o modelo funcional de arranjo, modelo similar ao adotado para documentos de cunho institucional.

Diante do levantamento realizado sobre a história arquivística desse conjunto documental, as questões norteadoras desta pesquisa são: Quais foram os elementos que concorreram para a construção do conjunto documental que hoje é reconhecido como o Arquivo Pessoal de Santos Dumont no CENDOC? Como reconhecer o acervo Santos Dumont à luz da teoria arquivística no que diz respeito ao campo dos arquivos pessoais?

A partir destes questionamentos, a pesquisa se fundamentou em problematizar o processo de constituição do conjunto documental que hoje é considerado o arquivo pessoal de Santos Dumont. Nesse sentido buscou-se, através de diálogos com a teoria arquivística, descrever a história arquivística do acervo, a fim de comparar o processo de produção desse arquivo com o de um arquivo pessoal.

Dentre os temas propostos pela arquivologia, a temática dos arquivos pessoais apresenta-se, comumente, provocativa. Isso porque os arquivos pessoais têm características que desafiam as propostas da teoria arquivística tradicional. Embora esta temática tenha se mantido à margem das discussões arquivísticas, atualmente vem ganhando força e ampliando discussões e conhecimento.

Ao tratarmos os arquivos pessoais, acabamos por aproximá-los, imediatamente, da realidade dos arquivos institucionais. Entende-se que há a necessidade de, primeiramente, compreender melhor o indivíduo e detentor do arquivo atuando, portanto, de maneira cuidadosa, visto que cada arquivo pessoal representa uma experiência nova e, como consequência, novos aprendizados. 
Primeiramente, destaca-se a importância do titular deste Arquivo Pessoal: Santos Dumont foi um aeronauta, esportista e inventor, um reconhecido herói brasileiro e patrono da Força Aérea Brasileira. Este conjunto documental, doado ao CENDOC em 2004 é reconhecido pela família e pelos pesquisadores como o seu arquivo pessoal.

Esse conjunto documental, apesar de não ser fruto das funções e atividades desenvolvidas por Dumont, é representativo de sua trajetória numa perspectiva pessoal, visto que esse conjunto fora acumulado a partir de clippings ora solicitados por Santos Dumont. Ou seja, no nível de conteúdo, os documentos refletem suas atividades. Esse conjunto hoje possui, portanto, força de representação documental sobre a vida de Santos Dumont e apresenta documentos provenientes da ação do Santos Dumont de agregar registros sobre sua vida.

É importante também que os usuários tenham acesso aos percalços a que esteve sujeita a constituição como arquivo e, portanto, tenha conhecimento da história arquivística desse conjunto documental.

Há que se destacar, ainda, a importância de se tratar esse arquivo de forma a dotá-lo das informações necessárias a compreensão de sua gênese e a relação com os agentes responsáveis pela sua criação e manutenção (guarda) no tempo, tanto o próprio Santos Dumont, como os familiares e o CENDOC.

$\mathrm{O}$ ato de pesquisar não é uma tarefa fácil, pois exige do acadêmico um tempo para a organização lógica de ideias. Demo (1996, p. 14) considera a pesquisa como uma atividade intelectual, nesse aspecto Minayo et al (2004, p. 23) corroboram, compreendendo-a como uma atividade básica das ciências na sua indagação e descoberta da realidade, pautada em uma atitude e uma prática de uma busca constante, definindo um processo inacabado e permanente. Nesse sentido, o foco é a busca por respostas para nossas indagações, vislumbrando a construção do presente artigo. A mesma é exploratória, tendo em vista que as pesquisas exploratórias são aquelas que têm por finalidade explicitar um fenômeno, objetivando um maior entendimento de um determinado problema. Nesse tipo de pesquisa, o pesquisador procura um maior conhecimento sobre o tema em estudo. (GIL, 2002). 
Assim, para cumprir os objetivos propostos, a mesma iniciou-se através de um levantamento bibliográfico, focado na busca de aportes teóricos sobre arquivologia, arquivo privado arquivo pessoal, entre outros. Gil (2002, p. 48) afirma que a pesquisa bibliográfica é desenvolvida a partir de material já elaborado, constituído principalmente de livros e artigos científicos. Assim, é importante embasar a pesquisa através de uma revisão da literatura, observando-se a relação entre o conteúdo levantado com a teoria já existente. Nessa fase da pesquisa, foram utilizadas as fontes secundárias, representadas por bibliografias publicadas sobre a temática estudada, tendo como fontes os artigos científicos, livros, teses, revistas, entre outras, possibilitando a coleta de informações importantes no processo inicial, tornando-se, no desenvolver da pesquisa, um facilitador para se chegar a um produto final.

Em paralelo, foi necessária a realização de uma entrevista com um dos doadores do acervo ao CENDOC, o Sr. Alberto Dodsworth Wanderley, sobrinho bisneto de Santos Dumont, para melhor analisar como o acervo foi moldado e o que exatamente fora doado. A entrevista, encaminhada via e-mail para o Sr. Alberto no dia 08 de julho de 2017, baseou-se no "Roteiro de entrevista com titular ou doador, sobre contexto de produção e guarda de arquivo pessoal", do Manual de Organização e Descrição de Arquivos Pessoais da Casa de Oswaldo Cruz de 2015. O questionário utilizado na entrevista será disponibilizado no Apêndice e cabe salientar que o mesmo fora posteriormente analisado. Além desta, outra entrevista foi utilizada como referência nesta pesquisa, realizada pelo jornal O Estadão, com familiares de Santos Dumont, intitulado, Aredescoberta de Santos Dumont, publicada no ano de 2015.

Visto que o objetivo desta pesquisa é descrever o processo de construção do que hoje se entende como o Arquivo Pessoal de Santos Dumont espera-se que, a partir discussão sobre arquivos pessoais e seus processos, justificar o termo "arquivo pessoal" para este conjunto documental, porque, apesar de não ser de fato o arquivo pessoal dele, representa e é identificado como exercendo esta função, a família inclusive assim nomeou o conjunto em Termo de Doação. Caso justifique-se assim nomeá-lo, com base na bibliografia sugerida, perceberemos que arquivos pessoais, nesse sentido, podem ser outros conjunto que não estão na literatura, 
contribuindo, então, para que mais trabalhos venham a ser desenvolvidos. Por fim, espera-se também que ele possa evidenciar o pai da aviação enquanto personagem histórico importante para o desenvolvimento do país e como seu acervo merece destaque na memória da aviação.

\section{ARQUIVO PESSOAL DE SANTOS DUMONT E SUAS HISTÓRIAS}

O acervo Santos Dumont, que está sob a guarda do Centro de Documentação da Aeronáutica (CENDOC), Organização Militar $(\mathrm{OM})$ da Força Aérea Brasileira (FAB). De acordo com Millar (2015, p. 155-156), nós arquivistas devemos explicar o que realmente possuímos, para justamente esclarecer essa posse de fundos, ou seja, há que se explicar a história temporal e espacial do fundo e deixar os usuários criarem as conexões e estabelecer suas próprias definições de "totalidade". Ou seja, os arquivistas necessariamente devem esclarecer questões acerca do produtor do arquivo, como e por que foram produzidos e acumulados e finalmente tratar da transferência de custódia deste arquivo para uma instituição arquivística, e o subsequente cuidado a esses documentos.

Portanto, cabe ao arquivista apresentar ao pesquisador tudo que envolve o fundo a ser consultado: explanações sobre a trajetória de vida do produtor, explanações sobre a reunião desses documentos por parte do produtor, possíveis intervenções por outros agentes, além do destino final do acervo a uma instituição de guarda, explicando como e em que termos se deram a doação e o processamento arquivístico para garantia do acesso.

O arquivista deve contar a história do fundo, explicando não só como os documentos foram produzidos, mas também por quais custodiadores estiveram passando pelo período de negociações para doação, por exemplo. No caso em questão, iniciaremos apresentando a trajetória de vida, pessoal e profissional, do produtor inicial do arquivo de Santos Dumont, a história da constituição do arquivo, visto que este, após a morte de seu produtor continuou sofrendo interferências no âmbito familiar e a transferência de custódia e de propriedade dos arquivos da família do produtor para o CENDOC, também será objeto de um relato explicativo. 
Apesar de o acervo, nos dias atuais, já estar tratado, houve a necessidade de entrevistar, não só um dos familiares de Santos Dumont, o Sr. Alberto Dodsworth Wanderley, filho do Tenente Brigadeiro Lavenère-Wanderley, o qual participou ativamente na constituição do arquivo, mas também outros militares, para entender os passos dados para efetivação da doação e após a doação, no período anterior a minha participação na organização do arquivo. É muito importante manter um bom relacionamento com os doadores do acervo, para que este contato permanente não se perca, haja vista a necessidade de sanar dúvidas ou esclarecer algum pesquisador, por exemplo. Esta é, necessariamente, uma tarefa de instituições de guarda.

O primeiro contato com o Sr. Alberto foi em 2014, ano em que eu cheguei ao CENDOC, logo que assumi o Projeto Acervo Santos Dumont, foi por telefone. Neste primeiro momento, por causa do andamento do projeto, até então, percebi certa dificuldade. Com o passar do tempo, e com os feedbacks dados ao Sr. Alberto, este passou a confiar no trabalho desenvolvido pela OM. Mesmo com a leitura de toda a biografia produzida, além de textos sobre Santos Dumont e, tendo participado da tradução dos documentos do acervo, percebeu-se a necessidade de uma entrevista, na expectativa de que conseguiríamos mais detalhes e informações sobre o conjunto documental.

Analisando metodologicamente, percebe-se a importância de ações por parte das instituições que façam a guarda de arquivos permanente, como arquivos pessoais, por exemplo, em recolher informações para realização de um cadastro dos doadores, na ocasião da doação. Mas é importante a manutenção de um contato permanente com os doadores, de modo a manter sempre atualizados seus cadastros, além de buscar maiores informações sobre os acervos.

A entrevista foi realizada com base num questionário de perguntas intitulado "Roteiro de entrevista com titular ou doador, sobre contexto de produção e guarda de arquivo pessoal" que faz parte, como anexo, do Manual de Organização e Descrição de Arquivos Pessoais da Casa de Oswaldo Cruz de 2015. Esta entrevista foi aplicada visando entender a formação e a custódia do acervo Santos Dumont. Segue o roteiro com as perguntas que compuseram o questionário. 
A- Perguntas sobre o Acervo de Santos Dumont.

1- O que motivou a doação do fundo e quem tomou a iniciativa de doá-lo.

2- Quem tomou a iniciativa de guardar os registros - o próprio titular ou outra pessoa?

3- Foi o próprio Santos Dumont o produtor do conjunto ou outra pessoa atuou na composição do arquivo?

4- Você saberia informar se houve alguma eliminação de documentos? Se houve, que critérios orientaram a eliminação?

5- Têm-se notícias da incorporação, ao arquivo, de conjuntos documentais ou itens provenientes de outras pessoas, como membros da família, colaboradores ou parceiros de trabalho?

6- Houve alguma transferência de custódia do conjunto documental ao longo do tempo?

7- Houve alguma dispersão, intervenção ou sinistro relacionados ao conjunto?

8- Há parcelas do arquivo sob outras custódias? (em outras instituições ou com outras pessoas, por exemplo).

9- Qual o valor atribuído ao arquivo pelos familiares? Por que é importante preservá-lo?

10- Por que o Centro de Documentação da Aeronáutica foi o escolhida pela família para a doação?

11- Tem algum documento que tem especial significado para a família e que gostaria de destacar?

O questionário, enviado ao Sr. Alberto Dodsworth no dia 08 de julho de 2017, por e-mail, sobre o que hoje se entende como o Arquivo Pessoal de Santos Dumont objetiva esclarecer a constituição e manutenção do mesmo, pelos produtores, visto a interferência de agentes no âmbito familiar, até a doação. Dessa forma, podemos compreender as características do acervo doado ao CENDOC.

Mesmo tendo trabalhado por dois anos com o acervo, eu sabia muito pouco sobre a história arquivística. Este questionário me auxiliou no desenvolvimento do artigo e, principalmente, me fez entender a real importância de se conhecer a 
história arquivística antes de se iniciar o processamento técnico de qualquer acervo. Conforme análise das respostas aos questionamentos apresentados, mais inquietações surgiram e com isso a necessidade de receber maiores informações sobre o acervo. Eu imaginava que tinha total conhecimento sobre o acervo e sua história, porém percebi que muito pouco sabia sobre tudo isso.

Com o intuito de fornecer mais informações e enriquecer este trabalho, como sugestão, o Sr. Alberto me sugeriu acessar as entrevistas realizadas com a família pelo Jornal O Estadão, em maio de 2015, as quais fizeram parte de um material sobre a vida de Santos Dumont. Conforme demonstra Abellás (2012, p. 75) deve-se considerar a importância das pesquisas sobre o produtor do arquivo e sua trajetória de vida, como caminho para a construção de uma organização arquivística que respeita ao mesmo tempo os princípios arquivísticos e a história (profissional e particular) do produtor.

\section{REFERÊNCIAS}

ABELLÁS, José Benito Yárritu. Arquivos pessoais, saberes coletivos: a organização da documentação pessoal e pública de cientistas - o caso Hussak. In: Silva, Maria Celina Soares de Mello; Santos, Paulo Roberto Elian dos. (org.). Arquivos pessoais: história, preservação e memória da ciência. Rio de Janeiro: Associação dos Arquivistas Brasileiros, 2012. p. 75-88.

ARQUIVO NACIONAL (Brasil). Dicionário brasileiro de terminologia arquivística. Rio de Janeiro: Arquivo Nacional, 2005.

ASSIS, Ailton. Um lampião dentro da mala: o arquivo pessoal de Octávio Pacheco, memória e autobiografia. 2009. 264 p. Dissertação (Mestrado em Letras) Universidade Federal de São João Del Rei, Minas Gerais, 2009.

BELLOTTO, Heloísa Liberalli. Arquivos permanentes: tratamento documental. 2. ed. Rio de Janeiro: FGV, 2004.

BELLOTTO, Heloísa Liberalli. Arquivos permanentes: tratamento documental. 4. ed. Rio de Janeiro: FGV, 2006.

BRASIL. Lei $\mathbf{n}^{\circ} \mathbf{8 . 1 5 9}$, de 8 de janeiro de 1991. Dispõe sobre a política nacional de arquivos públicos e privados e dá outras providências. Brasília, DF: Presidência da República, 1991. Disponível em:

http://www.planalto.gov.br/ccivil_03/LEIS/L8159.htm. Acesso em: 14 fev. 2015. 
CASANOVA, Eugenio. Archivistica. 2. ed. Siena: Lazzeri, 1928.

DEMO, Pedro. Educar pela pesquisa. Campinas: Autores Associados, 1996.

GIL, Antônio Carlos. Como elaborar projetos de pesquisa. 4. ed. São Paulo: Atlas, 2002.

HEYMANN, Luciana Quillet. Indivíduo, memória e resíduo histórico: uma reflexão sobre arquivos pessoais e o caso Filinto Müller. Revista Estudos Históricos, Rio de Janeiro, v. 10, n. 19, p. 41-66, 1997.

HEYMANN, Luciana Quillet. O indivíduo fora do lugar. Revista do Arquivo Público Mineiro, Belo Horizonte, v. 45, n. 2, p. 40-57, jul./dez. 2009.

LOPEZ, André Porto Ancona. Tipologia documental de partidos e associações políticas brasileiras. São Paulo: USP, 1999.

MILLAR, Laura Agnes. A morte dos fundos e a ressurreição da proveniência: o contexto arquivístico no espaço e no tempo. Informação Arquivística, Rio de Janeiro, v. 4, n. 1, p. 144-162, jan./jun. 2015.

MINAYO, Maria Cecília de Souza (org.) et al. Pesquisa social: teoria, método e criatividade. Petrópolis: Vozes, 2004.

PROCHASSON, Christophe. Atenção: verdade! Arquivos privados e renovação das práticas historiográficas. Revista Estudos Históricos. Rio de Janeiro, FGV, v. 11, n. $21,1998$.

SANTOS, Paulo Roberto Elian. Arquivos de cientistas: gênese documental e procedimentos de organização. São Paulo: Associação dos Arquivistas de São Paulo, 2012.

THOMSON, Alistair. Recompondo a memória: questões sobre a relação entre história oral e as memórias. Projeto História. São Paulo, n. 15, p. 51-84, 1997.

Recebido em 27/10/2019.

Aceito em 04/12/2019. 